\title{
PD50 - Impaired lung function in asthmatic schoolchildren - evaluation of risk factors
}

\author{
Hanna Knihtilä, Anne Kotaniemi-Syrjänen, Pekka Malmberg, Anna Pelkonen, Mika Mäkelä \\ From 3rd Pediatric Allergy and Asthma Meeting (PAAM) \\ Athens, Greece. 17-19 October 2013
}

In this retrospective study we investigated risk factors for impaired lung function based on medical records of asthmatic children treated in a tertiary hospital between October 2004 and December 2008. Baseline characteristics, lung function measurements and current medication were charted. Those 430 children with data on $\geq 2$ lung function measurements performed $\geq 5$ years apart, were included in the analyses.

Altogether 91 (21\%) children had abnormal findings in the first lung function measurement ( $\mathrm{n}=38 / 265$ in oscillometry performed at the median age of 4.2 years, and $\mathrm{n}=53 / 165$ in spirometry performed at the median age of 7.6 years) and $183(43 \%)$ in the last spirometry performed at the median age of 13.8 years. There were significant correlations between the oscillometry and last spirometry

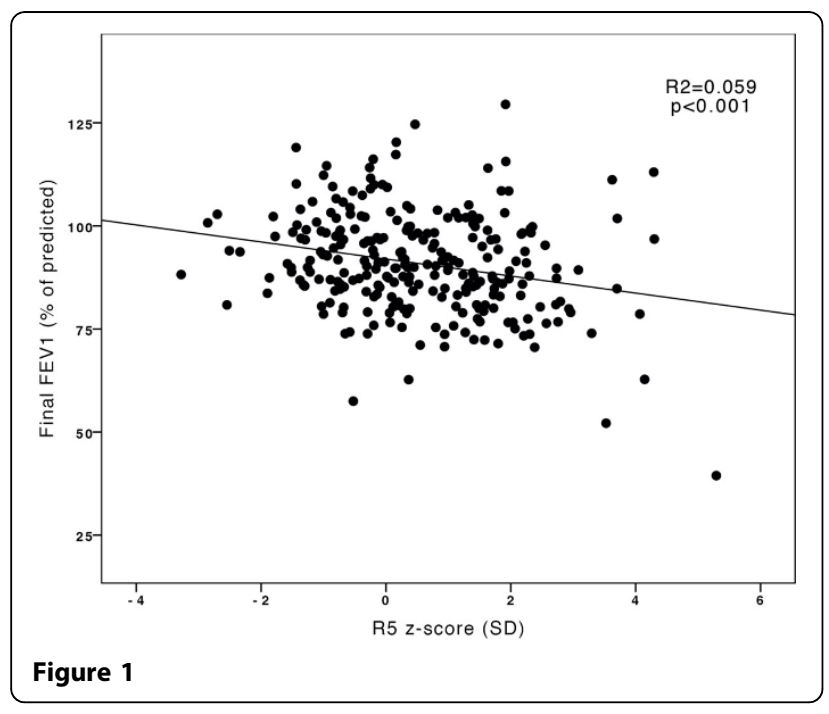

parameters: $r=-0.243$ between R5 z-score and FEV1 $(\mathrm{p}<0.001)$ (Fig.1), and $\mathrm{r}=-0.197$ between $\mathrm{R} 5 \mathrm{z}$-score and FEV1/FVC $(\mathrm{p}=0.001)$. Correlations between the first and last spirometry parameters were also significant: $r=0.547$ for FVCs, $\mathrm{r}=0.486$ and for FEV1s, $\mathrm{r}=0.450$ for FEV1/FVCs, and $r=0.496$ for $\ln ($ MEF50\%)s $(p<0.001$ in every comparison). There was a significant, albeit mild, correlation between the need of medication and decrease in FEV1/ FVC and MEF50\% ( $r s=-0.098 ; p=0.043$, and $r s=-0.097$; $\mathrm{p}=0.045$ ). In multivariate analyses, male gender, a birth weight of $<1500 \mathrm{~g}$, duration of asthma, and abnormal oscillometry or spirometry parameters in the first lung function measurement were significant risk factors for impaired lung function in adolescence.

In conclusion, male gender, a very low birth weight, and the duration of asthma interfere with the lung function development. In addition, impaired lung function appears to persist despite regular asthma control medication.

Published: 28 February 2014

doi:10.1186/2045-7022-4-S1-P50

Cite this article as: Knihtilä et al:: PD50 - Impaired lung function in asthmatic schoolchildren - evaluation of risk factors. Clinical and Translational Allergy 2014 4(Suppl 1):P50. 